NASA/TM-2005-213571

\title{
A Management Model for International Participation in Space Exploration Missions
}

Patrick J. George, Gary M. Pease, and Timothy E. Tyburski

Glenn Research Center, Cleveland, Ohio 
Since its founding, NASA has been dedicated to the advancement of aeronautics and space science. The NASA Scientific and Technical Information (STI) Program Office plays a key part in helping NASA maintain this important role.

The NASA STI Program Office is operated by Langley Research Center, the Lead Center for NASA's scientific and technical information. The NASA STI Program Office provides access to the NASA STI Database, the largest collection of aeronautical and space science STI in the world. The Program Office is also NASA's institutional mechanism for disseminating the results of its research and development activities. These results are published by NASA in the NASA STI Report Series, which includes the following report types:

- TECHNICAL PUBLICATION. Reports of completed research or a major significant phase of research that present the results of NASA programs and include extensive data or theoretical analysis. Includes compilations of significant scientific and technical data and information deemed to be of continuing reference value. NASA's counterpart of peerreviewed formal professional papers but has less stringent limitations on manuscript length and extent of graphic presentations.

- TECHNICAL MEMORANDUM. Scientific and technical findings that are preliminary or of specialized interest, e.g., quick release reports, working papers, and bibliographies that contain minimal annotation. Does not contain extensive analysis.

- CONTRACTOR REPORT. Scientific and technical findings by NASA-sponsored contractors and grantees.
- CONFERENCE PUBLICATION. Collected papers from scientific and technical conferences, symposia, seminars, or other meetings sponsored or cosponsored by NASA.

- SPECIAL PUBLICATION. Scientific, technical, or historical information from NASA programs, projects, and missions, often concerned with subjects having substantial public interest.

- TECHNICAL TRANSLATION. Englishlanguage translations of foreign scientific and technical material pertinent to NASA's mission.

Specialized services that complement the STI Program Office's diverse offerings include creating custom thesauri, building customized databases, organizing and publishing research results ... even providing videos.

For more information about the NASA STI Program Office, see the following:

- Access the NASA STI Program Home Page at http://www.sti.nasa.gov

- E-mail your question via the Internet to help@sti.nasa.gov

- Fax your question to the NASA Access Help Desk at 301-621-0134

- Telephone the NASA Access Help Desk at 301-621-0390

- Write to:

NASA Access Help Desk

NASA Center for AeroSpace Information 7121 Standard Drive

Hanover, MD 21076 
NASA/TM-2005-213571

\section{A Management Model for International Participation in Space Exploration Missions}

Patrick J. George, Gary M. Pease, and Timothy E. Tyburski

Glenn Research Center, Cleveland, Ohio

Prepared for the

First Space Exploration Conference: Continuing the Voyage of Discovery sponsored by the American Institute of Aeronautics and Astronautics Orlando, Florida, January 30-February 1, 2005

National Aeronautics and

Space Administration

Glenn Research Center 


\section{Acknowledgments}

The authors would like to thank the reviewers of this paper; Frank Alanis, Greg Schmitz, Bruce Manners, and Dave McKissock, all of whom have many years of experience working the ISS EPS, for their time and effort for ensuring the content is correct. Special thanks to Greg Schmitz for his valuable comments which improved the focus of the paper.

Available from

NASA Center for Aerospace Information 7121 Standard Drive

Hanover, MD 21076
National Technical Information Service 5285 Port Royal Road Springfield, VA 22100 


\title{
A Management Model for International Participation in Space Exploration Missions
}

\author{
Patrick J. George, Gary M. Pease, and Timothy E. Tyburski \\ National Aeronautics and Space Administration \\ Glenn Research Center \\ Cleveland, Ohio 44135
}

\begin{abstract}
This paper proposes an engineering management model for NASA's future space exploration missions based on past experiences working with the International Partners of the International Space Station. The authors have over 25 years of combined experience working with the European Space Agency, Japan Aerospace Exploration Agency, Canadian Space Agency, Italian Space Agency, Russian Space Agency and their respective contractors in the design, manufacturing, verification and integration of their elements electric power system into the United States onorbit segment. The perspective presented is one from a specific sub-system integration role and is offered so that the lessons learned from solving issues of technical and cultural nature may be taken into account during the formulation of international partnerships. Descriptions of the types of unique problems encountered relative to interactions between international partnerships are reviewed. Solutions to the problems are offered, taking into consideration the technical implications. Through the process of investigating each solution, the important and significant issues associated with working with international engineers and managers are outlined. Potential solutions are then characterized by proposing a set of specific methodologies to jointly develop spacecraft configurations that benefits all international participants, maximizes mission success and vehicle interoperability while minimizing cost.
\end{abstract}

\section{Introduction}

We are now in the partnership formulation period of time for the upcoming space exploration activities known now as the beginning of the Journey. Therefore, it is appropriate to present a technical perspective for consideration of the various committees which will guide the creation of future international partnerships. The authors' technical viewpoints are based on experiences while working on the electrical power system for the International Space Station (ISS) and with some of the International Partners (IPs). We hope to provide insight to the organizations responsible for the overall program planning which, perhaps unknowingly, have profound effects on the design, cost and operation of potential spacecraft even at these early stages.

This paper does not intend to address the establishment of accords and the political framework for international cooperation needed for future missions. The recent American Institute for Aeronautics and Astronautics' $7^{\text {th }}$ Workshop on International Space Cooperation held May 3-6, 2004 and others have addressed the continuing discussion on international cooperation at the top level. The authors have gained valuable experience working on the day-to-day level with the IP agencies and engineers. The obvious language and cultural differences have provided tremendous educational opportunities. Understanding other management structures, design processes, manufacture methods and verification approaches has broadened our appreciation for the accomplishments already made in building the ISS and increases our appreciation of the complexities necessary to achieve joint interplanetary travel. 


\section{Exploration, an International Endeavor}

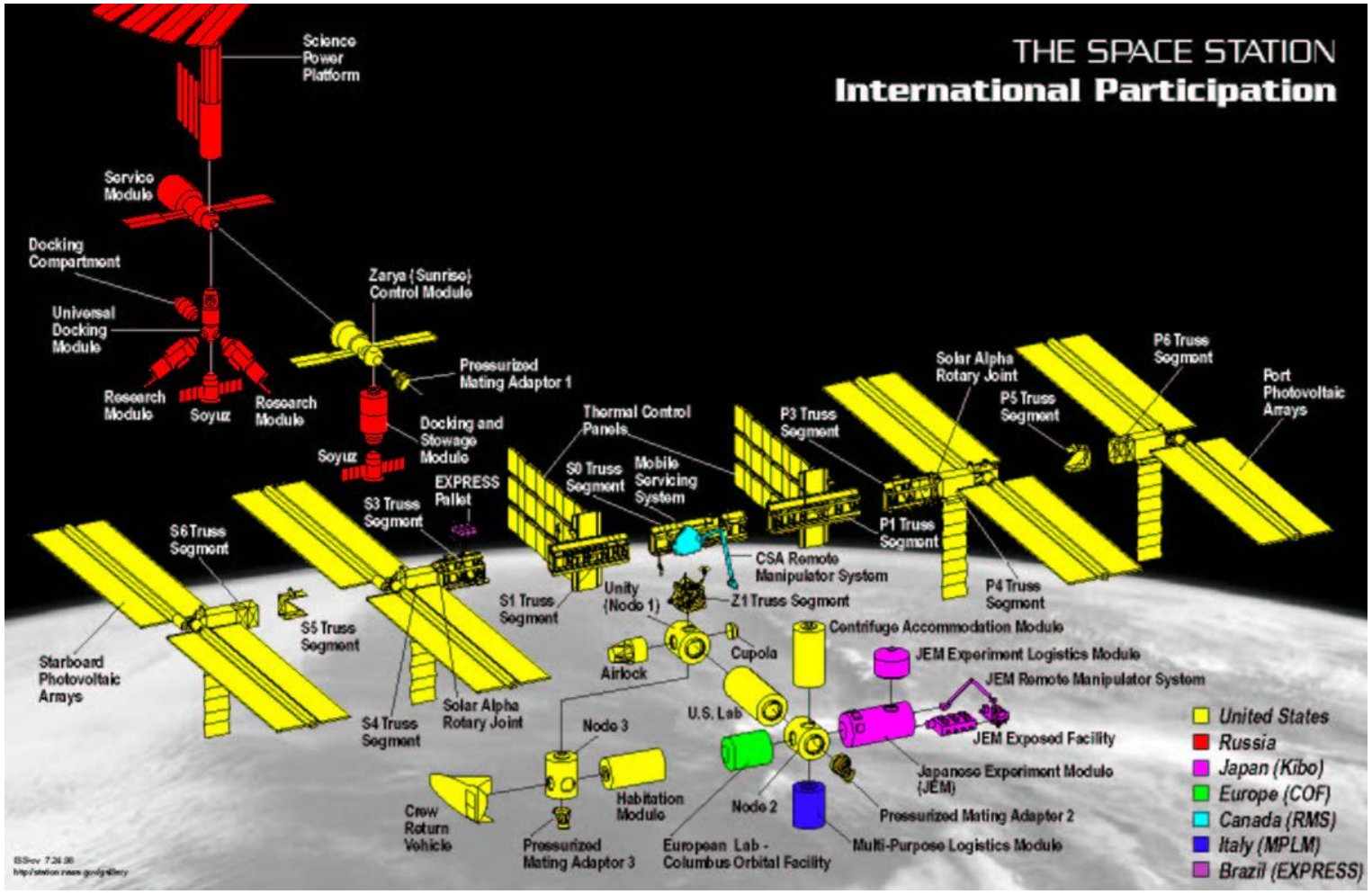

On January 14, 2004, at NASA Headquarters President Bush announced a new U.S. Space Policy. In part he said, "Inspired by all that has come before, and guided by clear objectives, today we set a new course for America's space program. We will give NASA a new focus and vision for future exploration. We will build new ships to carry man forward into the universe, to gain a new foothold on the moon and to prepare for new journeys to the worlds beyond our own." ... "We'll invite other nations to share the challenges and opportunities of this new era of discovery." The directive from President Bush gave NASA specific actions including, "Pursue opportunities for international participation to support U.S. space exploration goals. . ." and to "meet our international agreements by completing the assembly of the ISS including those provided by foreign partners." Since then, NASA has moved briskly forward to implement the President's Vision for Space Exploration. This moving forward has included a transformation of the agency into an organization better able to meet the goals of the Space Exploration Vision. NASA is implementing a new way of doing business that ensures affordability and sustainability of space missions. For an endeavor as complex as a mission to Mars or other planets we believe that international partnerships are required. The cost to design, build and operate spacecraft capable of human transportation to other planets will be greater than any one nation can afford. The authors believe that interplanetary travel is also an endeavor which should be performed with the commitment and cooperation of all nations on behalf of the people of Earth.

NASA now has written direction and actions demonstrating commitment on behalf of the U.S. to work with other countries in pursuit of the interplanetary journey. Some foreign countries have also shown interest in working with the U.S. for the exploration of space by attending the NASA International Workshop on Creating New and Sustainable Space Exploration held in Washington DC on November 16-18, 2004. ${ }^{2}$ This meeting was attended by 19 space organizations including China and India. The objectives of this conference were to provide a forum for international agencies to exchange information on their plans for exploration and to discuss possible areas of common interest. The presentations and related deliberations will serve as the basis for each country's assessment of their particular level of future involvement. Much more discussion is needed to build trust and mature the relationships necessary to forge the organization and agreements for an international space alliance dedicated to exploration. Future opportunities to continue the dialogue must include industry as industry has an obviously critical role not only in designing and building spacecraft but also in commercial utilization of space. A forum for further discussion will be the International Conference on Cooperation in Space to be held during the Earth and Space Week conference, February 12-20, 2005 in Europe. 
Recent examples of international cooperation in space science projects include the Swift (Gamma-Ray Burst Detection Spacecraft)) and the Solar and Heliospheric Observatory (SOHO) missions which provided a basis for further such experiments. The Cassini-Huygens mission involving NASA, the European Space Agency (ESA) and the Italian Space Institute (ASI) has demonstrated collaboration on many levels. The NASA built Cassini spacecraft provided both the transportation and communications links to Earth for ESA's Huygens probe as Huygens descends to Saturn's moon Titan. Huygens uses ASI's science instruments to collect atmospheric data. The recent demonstration of high data rate transmission between NASA's Opportunity rover on the Mars to ESA's orbiting spacecraft Mars Express and then back to Earth was possible by using a common protocol developed by the International Consultative Committee for Space Data Systems.

Perhaps the most ambitious and certainly the most complex example of international cooperation in space exploration to date is the ISS. There are 16 countries participating at various levels. The authors suggest that the ISS fills a role of providing a perfect, low Earth orbiting platform and operations base for the international mission to Mars on which to perform technological experiments and investigations on humans. We need to increase our knowledge and understanding of living and working in space before any long duration travel is undertaken. The ISS is such a platform and can be utilized specifically in support of the Exploration vision.

The U.S. has the role of major contributor, systems integrator and sub-system provider for the ISS. NASA, and Boeing as the lead integration contractor, has the responsibility to ensure safe operation of the ISS. The Russian space agency, Roskosmos, supplied the first module which was the foundation of the ISS. Later the Russian partners expanded their contribution to supply electrical power and communications and the Russian Partners play a major role in determining the use and performance of ISS. Since the Columbia disaster, the Russian partners have stepped in and provided all of the re-supply flights, allowing the ISS to remain operational. The Canadian Space Agency (CSA) designed and built the robotic arm used to assemble the station and to perform cargo offloading and maintenance. ESA and the Japan Aerospace Exploration Agency (JAXA) have built modules designed to conduct experiments and are currently awaiting the return of NASA's Space Transportation System (Space Shuttle) to flight status. The international cooperation already achieved by formulating the agreements for the ISS and by operating as an international partnership has established the groundwork for space exploration partnerships and collaboration.

As with any complex endeavor there have been challenges. Some of these are a direct result of a space exploration program with broad international participation. In the next section we provide an analysis of selected challenges drawn from our ISS electric power system experience.

\section{Some Challenges Encountered with the International Space Station}

The following are examples of notable challenges that occurred while working the integration of the ISS electrical power system.

\section{A. System Trade Studies}

Some of the first features established when designing the electrical power system for a spacecraft are the current flow methods [alternating current (AC) versus direct current (DC)], reference voltage potential and the operating voltage range. Basically, these are electrical system characteristics which define the design parameters for all of the loads which connect to the system such as distributed power converters and experimental payloads. During the initial stages of the ISS design in the U.S. there were many "spirited" meetings in which the pro's and con's of these design features were debated. Eventually the design we currently have emerged. We suspect that our Russian partners probably had the same type of debates during the time that they were designing their space station MIR.

Having to transfer power to and from differing systems requires additional converters and equipment adding mass and volume. Additional converters and equipment increases the infrastructure necessary to support a crew and perform experiments which causes both the initial and maintenance costs to go up. The complexity is also raised thus decreasing the overall reliability. The number of interfaces needing to be defined and negotiated is increased as well as the support of related documentation.

This paper is not the forum to discuss electrical system design. However, it is necessary to point out that different approaches to designing electrical systems could result in problems when they have to work together in one system.

\section{B. Engineering and Design Changes}

There are many causes for requirements and design changes in large scale, long term international projects such as the ISS or the proposed Vision for Space Exploration. Requirements may have been written or interpreted incorrectly, hardware may perform as designed, but may not meet functional mission requirements, and mission 
requirements may change over time. Changes internal to NASA are costly, but the cost of even minor changes to a large international project such as ISS can be staggering.

A Change Request (CR) must be submitted to formally document modifications to the ISS. The change must be reviewed and dispositioned by each IP affected. The CR must also be cross checked against higher or lower level documents impacted. This is an expensive and time consuming process. One particular example of this is when an additional power feed was added to the Centrifuge Accommodation Module (CAM) design. It was proposed to reuse an existing on-orbit vestibule jumper. This jumper, intended for a single use, is to provide the Exposed Logistics Module-Pressurized Section (ELM-PS) life support power while temporarily docked to Node 2. Reusing this vestibule jumper was a cost savings measure, but ended up costing more than fabricating a new cable. The high cost of reusing this jumper was a direct result of the change process required for a large multinational project such as ISS.

The cost of making engineering and design changes will increase as the number of IPs increases; however, steps can be taken to streamline the process and minimize costs. Any model chosen for international participation in the Vision for Space Exploration should be designed to minimize cost impacts for engineering and design changes.

\section{Verification}

Verification is necessary to assure that subsystems meet functional and safety requirements with an acceptable level of risk. This can be a difficult within NASA, but if the program involves multiple countries, it can be much more contentious because verification activities are expensive and points of view are diverse. NASA is the ISS lead integrator and in this capacity has levied verification and flight certification requirements on the IPs. Many of the ISS IPs consider the level of verification required by NASA to certify that components, subsystems and elements meet or exceed functional and safety requirements, are unnecessarily stringent based on the countries' past experiences with flight hardware and perceived level of acceptable risk. Even when verification requirements are clearly defined and agreed upon, the methods used to show compliance may not be acceptable. The range of extremes run the gamut from "ship and shoot" to complete integrated testing as performed during the ISS MultiElement Integrated Tests performed at Kennedy Space Center (KSC) on many of the domestic and international ISS elements.

For example NASA performed a Pre-Qualification Review (PQR) of the Japanese Experiment Module (JEM) at Tsukuba Space Center in Japan and a Qualification Review (QR) of the Attached Pressurized Module (APM) at ESA's contractor facility in Germany to verify the APM before shipment to KSC. Typically NASA uses Verification Closure Notices (VCN) to show compliance to requirements, and Verification Compliance Matrixes (VCM) to show traceability. ${ }^{5}$ Japanese Aerospace Exploration Agency (JAXA) provided a VCM for the PQR in which almost every requirement was closed by the same 3000 page report without reference to where in the report the requirement was closed. Other reports used for closure where written in Japanese with a single paragraph English summary. ESA used a similar method to show requirement compliance at the APM QR in Germany. JAXA and ESA thought they were providing sufficient data to close requirements and they may have done so, but it was not in a form that was acceptable to NASA. This disconnect was created in part by cultural and language barriers.

The problems described above can be avoided if there were better understanding of each IPs verification methods. Advanced planning and improved communication are key to successful joint verification activities.

\section{Communication}

Based on our EPS experience we believe that successful completion of a multinational project requires ongoing communication and collaboration at all levels. There are several obstacles to overcome for this to happen. Participants are on different continents, speak different languages and have culturally different expectations. These challenges must be overcome regardless of what notional management model is used to implement the Vision for Space Exploration. It would be advantageous for NASA to make full use of state of the art training and technology to improve communication and collaboration. Web based meetings are an example of technology not fully utilized.

\section{E. Barter Agreements}

Barter agreements were one of the methods used for sharing cost and allocating work to international participants of the ISS. Barter agreements are negotiated and formalized at the highest levels of an organization; however, barter agreements can have a negative impact on the success of a project at the subsystem level. One example of this is the barter agreement between National Aeronautics and Space Administration (NASA) and the JAXA. ${ }^{3}$ In basic terms JAXA agreed to build the CAM in exchange for NASA launching the Japanese Experiments Module (JEM) on the Orbiter. 
A barter agreement may seem like a win-win situation for both international participants at the outset, but in the long run may lead to conflict, higher cost, schedule delays and ultimately the threat of cancellation. When the agreement is reached, both parties enter into the agreement based on their assessment of the anticipated cost for their part of the exchange. These assessments must be done based on the maturity of the mission requirements at that time. Long term projects such and the ISS and the Vision for Space Exploration may have drastically changing mission requirements and or varying mission requirement interpretations over time.

The barter arrangement leads to conflict at the subsystem level because any requirement that was interpreted incorrectly at the outset will require engineering changes which could result in cost and schedule impacts. These impacts that occur at the subsystem level were not accounted for when the initial barter took place. If one of the parties allocated $\$ 100 \mathrm{M}$ for the project and it will now cost $\$ 200 \mathrm{M}$, the project itself may be in jeopardy. It is the authors, experience that the scrutiny caused by a barter agreement at the subsystem level does not promote an environment of open collaboration, but one of defensive self interest. The use of barter agreements for space exploration should be structured in such a way to promote open collaboration and enhance subsystem development.

\section{F. Export Control}

Export control regulations are an inherent part of international projects. These restrictions are designed to protect national interests, but often can unnecessarily prevent communication and collaboration that enhance project success. Personnel working on any international project should become familiar with export control regulations because they can be held personally liable for any violations. Export control regulations have created some roadblocks to the design, development and integration of the ISS.

The Automated Transfer Vehicle (ATV) and H-II Transfer Vehicle (HTV) are un-manned re-supply vehicles servicing the ISS. The ATV is being developed by the European Space Agency (ESA) and will be launched into Space by Ariane 5 from French Guiana. ${ }^{4}$ The HTV is being developed by JAXA and will be launched from Tanegashima Space Center in Japan. NASA and its contractors have an obligation to support ATV and HTV development, integration and operations as defined in ISS Memoranda of Understanding (MOUs).

The majority of items that make up the ISS fall under the jurisdiction of the U.S. Export Administration Regulations (EAR) under the classification 9A004. The ATV and the HTV are different from most ISS hardware because they are classified as Category XV defense articles under the International Traffic in Arms Regulations (ITAR). The ITAR classification reflects the more significant military applications of the technology involved in an orbital transfer vehicle. This more stringent military classification has created problems for NASA in the development and integration of the HTV and ATV.

One such problem was encountered during the HTV preliminary design review when it was discovered that HTV EPS single bus architecture design did not meet NASA safety requirements for free flying vehicles near the ISS. Export control regulations levied on the HTV prevent NASA from supplying any design information to JAXA. NASA could not coordinate with JAXA on a new design that would meet safety requirements. In this case the export control regulations prevented NASA from sharing valuable knowledge and experience in the design of both manned and unmanned space vehicles thus unnecessarily increasing cost and delaying schedule. International space exploration collaborations may want to lobby for less strict export control classifications for defendable non-military applications.

\section{G. Import/Export of NASA Ground Support Equipment (GSE)}

The verification of the ISS IP elements requires shipment of test equipment from the United States to countries such as Japan, Germany and Italy. ${ }^{8,9,10}$ The shipment of this equipment is also subject to export control regulations as well as the InterGovernmental Agreement (IGA) that was established by IP countries working on the ISS. The IGA assures that no duties or taxes will be paid when shipping ISS hardware to or from international partner countries. NASA shipped ISS power system test equipment to Tsukuba Space Center in Japan in order to perform the Japanese Experiments Module (JEM) Step 2 Joint EPS Verification Test. ${ }^{10}$ The JEM Step 2 test was performed from November 6 through November 29, 2001 as part of an overall verification plan that the JEM EPS performance requirements. ${ }^{7}$ There was a blanket export license in place for exporting ISS hardware, but many of the items needed for the Step 2 test were not on the list. ${ }^{6}$ This created the necessity for NASA to obtain a temporary export license, and it was beneficial to put all the equipment on the temporary license. There were also problems with execution of the IGA in Japan. Each partner country is to develop a marking process as defined in IGA article 19 to assure that when the equipment arrives at customs there are no duties or taxes charged. JAXA was in the process of developing the marking procedure at the time of shipment, so when the equipment arrived in Japan it was held in customs for over a week. The existing complexities involved with shipping assets to and from partner countries can be time 
consuming and costly. Any new space exploration initiative should develop strategies to simplify the process and assure that those strategies are implemented.

\section{Some Proposed Methodologies for Managing an International Interplanetary Spacecraft}

The following is a small set of spacecraft configurations used to illustrate the effects of selecting international partnership arrangements on a sub-system level. The authors recognize some configurations may not be feasible but are chosen here only to demonstrate an extreme range of ideas. No matter which model is used, safety and mission success are issues which must be addressed by all partners.

\section{A. Independent Modules “Train”}

One basic overall design solving many of the subsystem issues is the autonomous or "Train" arrangement. A simplistic pictorial view of this concept is shown in figure 1 . In this configuration, the lead integrator would provide the propulsion system and overall structure to which the other modules would attach. No transfer of electrical power occurs. Each module would be independent and self-contained. This model requires few interfaces between partners and thus minimizes communication problems and reduces the number of joint verification activities. This model does not support full collaboration between IPs.

\section{B. Sub-system by Partner "UN"}

A sub-system by partner configuration assigns each willing partner with development and operation of a major sub-system. This is the "United Nations" (UN) model, shown in figure 2 as a pictorial representation. Envision an arrangement where each nation bids on a subsystem according to their technical and manufacturing ability, and financial capabilities. All equipment would be designed, produced and tested by the developer thus reducing the number of joint verification activities. All partners would have to incorporate the sub-system equipment into their modules. Details of how to implement this concept could be made by a board consisting of participant members. The lead integrator must assure that the bidding process is implemented such that it promotes international participation and accounts for political, financial and technological factors.

This model minimizes the number of IP interfaces and maximizes interoperability on a subsystem basis.

\section{Joint Design and Development “Joint"}

This configuration is perhaps the most complex and falls at one of the extreme ends of the scope of design. Figure 3 is a representation of a single completely integrated model. All sub-systems would be negotiated between all partners to form one system known as the "Joint" model. Sub-systems would be designed by committee and supplied by the lowest, most reliable bidder. All interfaces would be defined but a burden would be placed on all nations to agree upon the details for all systems and sub-systems before construction could start. Any changes to the design must be worked and
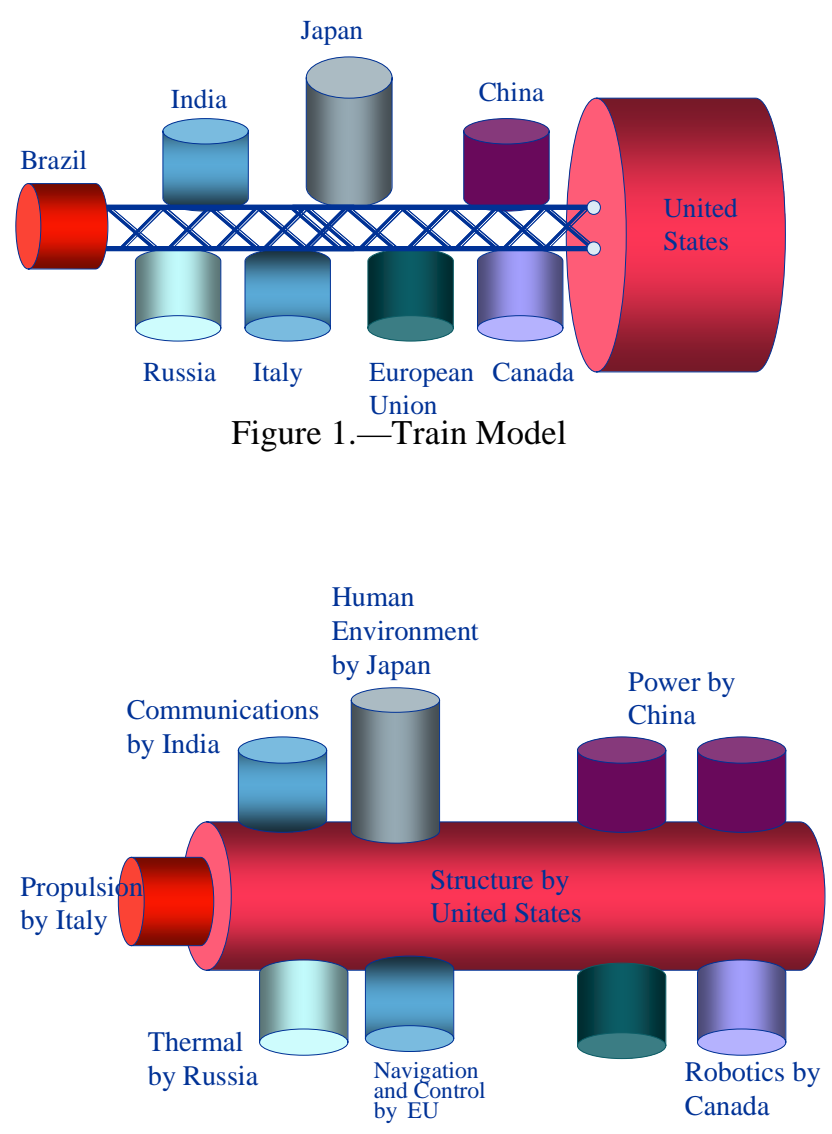

Figure 2.-_UN Model

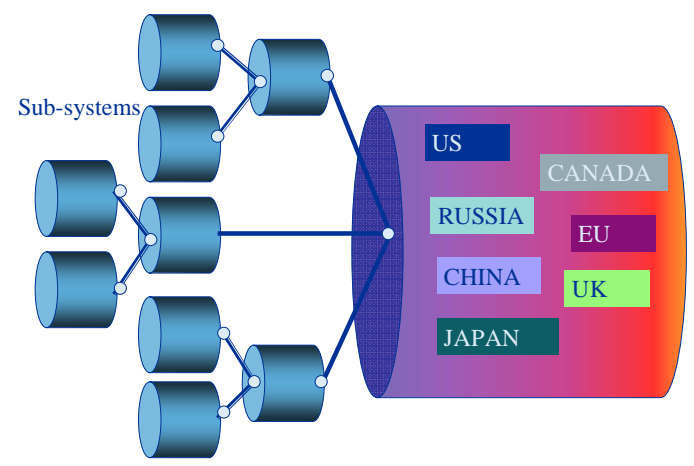

Figure 3.—Joint Model 
approved by all partners having a dramatic effect of slowing development and construction. This design exacerbates most of the aforementioned problems and does not offer many solutions. Design by multiple committees would create significant communications, verification and interface issues.

\section{Commercial Structure "Commercial”}

In the model for a highly competitive environment, the international partners pool their resources and grant contracts to commercial contractors. Figure 4 is a representation of such an idea. The best equipment and sub-system design wins no matter in which country the contract is located. National space agencies would define basic performance characteristics but would not participate in the design of the spacecraft. Resolution of all system and sub-system interface issues would be left to the commercial teams. It is

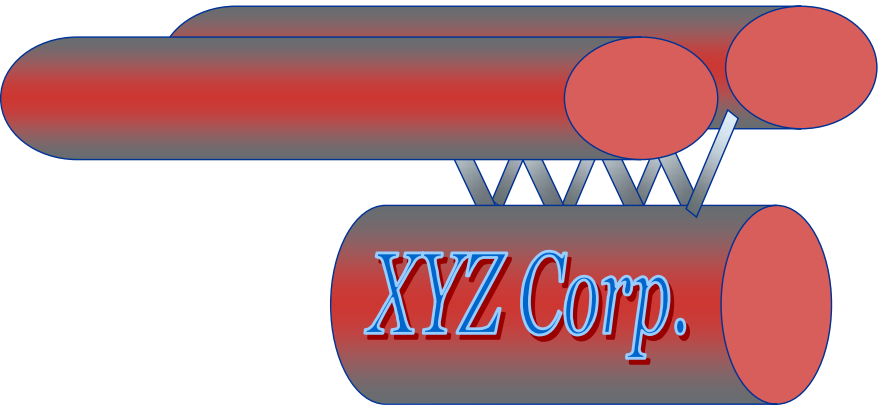

Figure 4.-Commercial Model believed that the prospect of financial reward would be sufficient for the contractors to overcome language and cultural barriers. The driver to achieve cost and schedule progress of sub-system interfaces would be based on payment for actual progress. Development of interfaces and activities associated with joint verification are minimized in this design and presents a viable option to be considered.

\section{Conclusion}

In this paper we have examined some of the issues posed in design, development, test, evaluation and operation of the ISS electric power system. We have provided notional models of international partnerships for consideration. It is the purpose of this paper to assist the Exploration Program formulators by advancing ideas such that some of the problems associated with working with international partners to jointly design and operate an electrical power sub-system for a spacecraft would be reduced thus making the exploration goals more achievable. In consideration of the factors previously discussed regarding the interaction with international partners, it may be is easier to convey the conclusion through the formation and explanation of a decision space.

Our experience leads to the conclusion that at a minimum, the following factors must be considered as drivers for international participation in space exploration.

- The number of nations involved,

- The higher the number of participants the longer it will take to forge and implement agreements and changes. Therefore, if broad international participation is desired then, the program must be prepared to invest the necessary time in forging the agreements and carrying the implementation down to the system and subsystem level at the start of the program thus avoiding some of the challenges that have been experienced on the ISS EPS.

- The level of technical autonomy between partners

- Technical autonomy is defined here as the degree to which a system is subject to national standards and practices versus international standards and practices. No technical autonomy means $100 \%$ use of international standards and practices and $0 \%$ use of national standards and practices. Full technical autonomy means $0 \%$ use of international standards and practices and $100 \%$ use of national standards and practices.

- If zero technical autonomy is desired, then just as above, time will be required to reach agreement on the international standards and practices that will be used.

- The level of interoperability between partners

- Interoperability is defined for this paper as the degree to which components of a system are able to operate without alteration to achieve $100 \%$ of operational characteristics when introduced anywhere throughout the system. For example if there is an internationally developed spacecraft then, an electrical power converter from country A could be substituted for the converter of country B and the overall spacecraft operation would be unchanged, the specific operation at the replaced converter site would be unchanged. This circumstance is $100 \%$ interoperability. The converse is $0 \%$ interoperability; that is, if each country has unique hardware then there is no interoperability. 


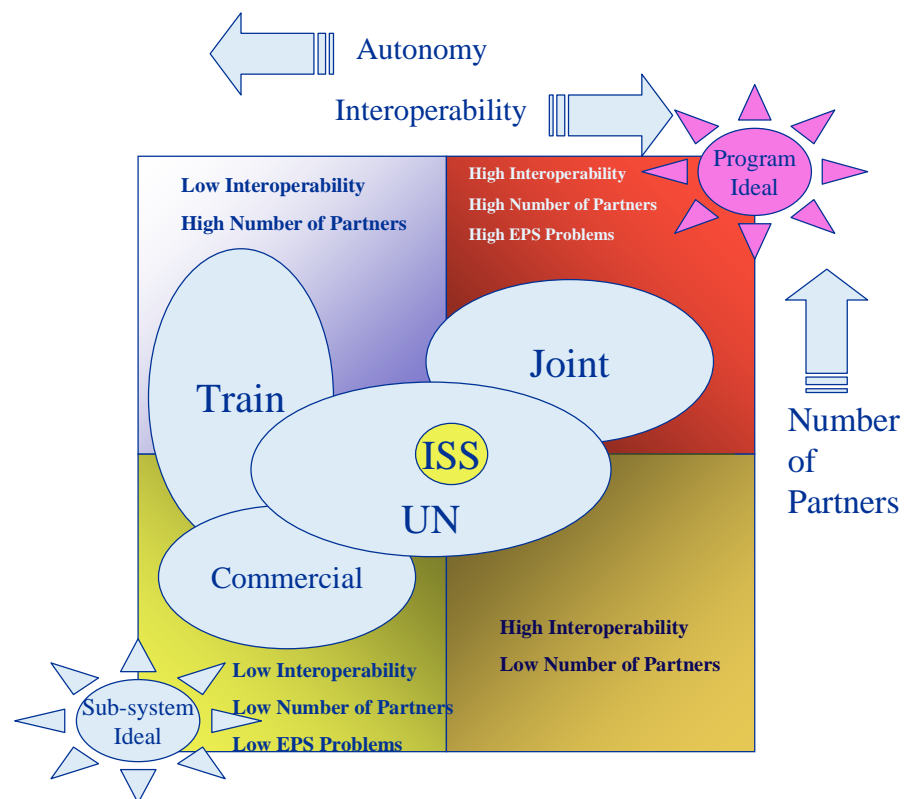

Figure 5.-Model Interpretation Diagram (as a reference, the ISS is chosen as the center of the diagram).
- For extended human interplanetary travel $100 \%$ interoperability is assumed. Logistics inventory must be minimized and carrying multiple version of EPS hardware would seem to not be in the mission's best interests.

Based on our experience and our view through the lens of the EPS, there seems to be a dichotomy between creating a program ideal and a sub-system developer ideal as shown in figure 5. If broad international participation is desired the autonomy will be reduced, interoperability could be increased, EPS subsystem challenges will also increase. Program formulators must expect an increase in difficulty and time needed to resolve differences.

Clearly, our point of view is limited by our experience and other models can be implemented. Our goal was to join the dialogue of international cooperation and provide a point of view from a hands-on perspective. Other challenges beyond our experience and thus not covered in this paper may mandate the use of another model of international cooperation.

\section{References}

${ }^{1}$ Bush, G. "A Renewed Spirit of Discovery: The President's Vision for U.S. Space Exploration,” http://www.nasa.gov/pdf/55583main_vision_space_exploration2.pdf

${ }^{2}$ http://www.aiaa.org/content.cfm?pageid=230\&lumeetingid=1223\&viewcon=other302\&id=302

${ }^{3}$ Waddell, J.B., Yamaura, Y., “Agreement in Principle JEM Launch Offset,” September 1997, Tsukuba, Japan.

${ }^{4}$ http://www.estec.esa.nl/spaceflight/atv.htm

${ }^{5}$ Garcia, R., “NASA/ESA/ASI Nodes 2/3 Project Joint Implementation Plan,” Draft \#7, SSP50698, October 2003, Johnson Space Center, Houston Texas.

${ }^{6}$ Geisz, P., “International Space Station Comprehensive Export License,” 202-358-1620, NASA Export Control Program, September 1999, NASA Headquarters, Washington DC.

${ }^{7}$ Fassburg, D.H., "Electric Power Specifications and Standards Volume 1: EPS Electrical Performance Specifications," SSP30482 Volume 1 Rev C, July 1997, Johnson Space Center, Houston, Texas.

${ }^{8}$ Aycock, D. Jr, “Node 2 NASA/ASI Bilateral Integration \& Verification Plan,” SSP 50281, January 2003, Johnson Space Center, Houston, Texas.

${ }^{9}$ Monahan, F., “NASA/ESA Bilateral Integration \& Verification Plan,” SSP50034 Rev C, March 2003, Johnson Space Center, Houston, Texas.

${ }^{10}$ Youmans, J., “NASA-NASDA JEM Bilateral Integration and Verification Plan,” SSP 50035 Rev B, November 2003, Johnson Space Center, Houston, Texas. 


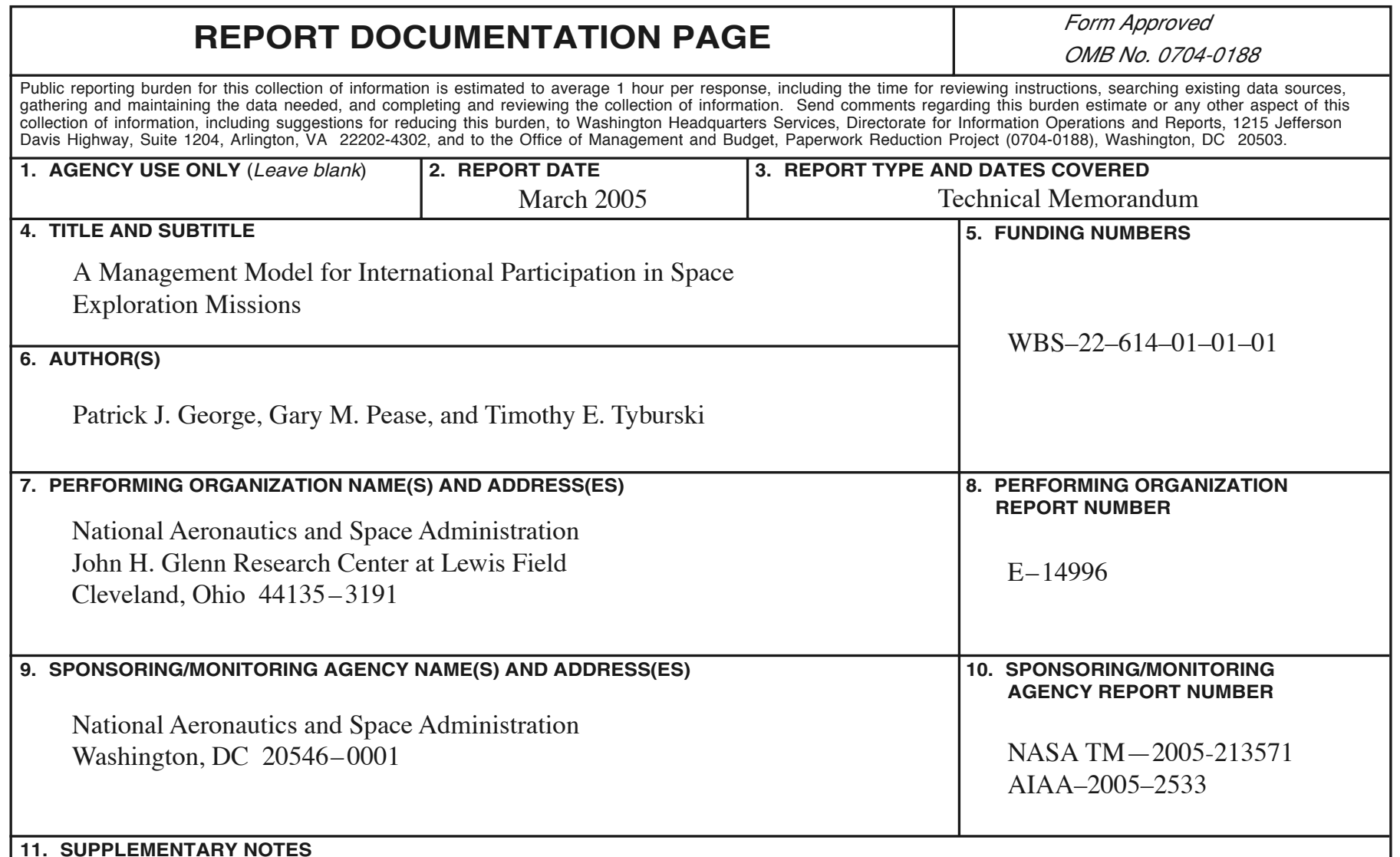

\section{SUPPLEMENTARY NOTES}

Prepared for the First Space Exploration Conference: Continuing the Voyage of Discovery sponsored by the American Institute of Aeronautics and Astronautics, Orlando, Florida, January 30-February 01, 2005. Responsible person, Patrick J. George, organization code PTE, 216-433-2353.

12a. DISTRIBUTION/AVAILABILITY STATEMENT 12b. DISTRIBUTION CODE

Unclassified - Unlimited

Subject Categories: 12 and 18

Available electronically at http://gltrs.grc.nasa.gov

This publication is available from the NASA Center for AeroSpace Information, 301-621-0390.

13. ABSTRACT (Maximum 200 words)

This paper proposes an engineering management model for NASA's future space exploration missions based on past experiences working with the International Partners of the International Space Station. The authors have over 25 years of combined experience working with the European Space Agency, Japan Aerospace Exploration Agency, Canadian Space Agency, Italian Space Agency, Russian Space Agency, and their respective contractors in the design, manufacturing, verification, and integration of their elements electric power system into the United States on-orbit segment. The perspective presented is one from a specific sub-system integration role and is offered so that the lessons learned from solving issues of technical and cultural nature may be taken into account during the formulation of international partnerships. Descriptions of the types of unique problems encountered relative to interactions between international partnerships are reviewed. Solutions to the problems are offered, taking into consideration the technical implications. Through the process of investigating each solution, the important and significant issues associated with working with international engineers and managers are outlined. Potential solutions are then characterized by proposing a set of specific methodologies to jointly develop spacecraft configurations that benefits all international participants, maximizes mission success and vehicle interoperability while minimizing cost.

\begin{tabular}{|c|c|c|c|}
\hline \multicolumn{3}{|l|}{ 14. SUBJECT TERMS } & $\begin{array}{c}\text { 15. NUMBER OF PAGES } \\
14 \\
\end{array}$ \\
\hline
\end{tabular}



